\title{
Effect of La Doping on the Electronic Structure of $\mathrm{SrTiO}_{3}$
}

\author{
Shigenori MATSUSHIMA, Shigemi KOHIKI* and Masaoki OKU** \\ Department of Chemical Engineering, Kitakyushu National College of Technology, \\ 5-20-1, Shii, Kokuraminami-ku, Kitakyushu-shi 802-0985 \\ * Department of Materials Science, Faculty of Engineering, Kyushu Institute of Technology, \\ 1-1, Sensui-cho, Tobata-ku, Kitakyushu-shi 804-8550 \\ **Institute for Materials Research, Tohoku University, 2-1-1, Katahira, Aoba-ku, Sendai-shi 980-8577
}

\section{$\mathrm{SrTiO}_{3}$ 電子構造における $\mathrm{La}$ の添加効果}

\author{
松嶋茂憲·古曳重美* ·奥 正興** \\ 北九州工業高等専門学校化学工学科, 802-0985 北九州市小倉南区志井 5-20-1 \\ *九州工業大学工学部物質工学科, 804-8550 北九州市戸畑区仙水町 1-1 \\ **東北大学金属材料研究所，980-8577 仙台市青葉区片平 2-1-1
}

\begin{abstract}
For undoped-SrTiO ${ }_{3}$ and La-doped $\mathrm{SrTiO}_{3}$ single crystals, X-ray photoemission spectroscopy (XPS) measurements were performed with monochromated $\mathrm{Al} K \alpha$ radiation. Valence band (VB) spectra of as-fractured $\mathrm{SrTiO}_{3}$ exhibit two peaks, $\mathrm{P} 1$ and $\mathrm{P} 2$, arising from the $\mathrm{O} 2 \mathrm{p} \pi$ and $\mathrm{O} 2 \mathrm{p} \sigma$ bonding orbitals, respectively. Upon adding $3.0 \mathrm{~atm} \%$ of $\mathrm{La}$ to $\mathrm{SrTiO}_{3}$, the valley between $\mathrm{P} 1$ and $\mathrm{P} 2$ disappears in the VB spectrum. Calculated VB spectra obtained from a molecular orbital calculation reproduce well the experimental XPS spectra for the samples.

[Received December 9, 1999; Accepted February 16, 2000]
\end{abstract}

Key-words : $\mathrm{SrTiO}_{3}$, La-doped $\mathrm{SrTiO}_{3}$, X-ray photoemission spectroscopy, Valence band, Electronic structure, Density of state, Molecular orbital calculation

1. Introduction

Stoichiometric $\mathrm{SrTiO}_{3}$ is highly insulating and has a large optical band gap of about $3.27 \mathrm{eV}$, but a slightly reduced $\mathrm{SrTiO}_{3}$ shows n-type semiconduction. ${ }^{1), 2)}$ The improvement of the electric conductivity can also be realized by doping atoms of different valencies into $\mathrm{SrTiO}_{3}$. To research the nature of the physical properties of $\mathrm{SrTiO}_{3}$, many band calculations and much experimental work have been performed. ${ }^{3)-13)}$ However, theoretical investigations for doped $\mathrm{SrTiO}_{3}$ systems have not been reported. The purpose of the present study is to provide experimental and theoretical information on the electronic structure of undoped and $\mathrm{La}^{-}$ doped $\mathrm{SrTiO}_{3}$ with the cubic perovskite-type structure. We performed X-ray photoemission spectroscopy (XPS) measurements for these single crystals and compared the results with the theoretical ones obtained from a molecular orbital (MO) calculation.

\section{Experiment and calculation}

XPS measurement was carried out using a Surface Science Laboratories model SSX-100 spectrometer with a monochromated $\mathrm{Al} \mathrm{K} \alpha \mathrm{X}$-ray source. The XPS spectra were collected from single crystals fractured in situ in ultrahigh vacuum (UHV). Fracturing single crystals in situ in UHV is the only reliable way of preparing almost perfect and stoichiometric surfaces that are indispensable for obtaining highly accurate data that can be compared with the theoretical calculation. The spectrometer was calibrated utilizing the peak originating from $\mathrm{Au} 4 \mathrm{f}_{7 / 2}(83.79 \mathrm{eV})$ and the full width at half maximum (FWHM) of $\mathrm{Au} 4 \mathrm{f}_{7 / 2}$ was $1.03 \mathrm{eV}$. In this experiment, the undoped and $\mathrm{La}(3 \mathrm{~atm} \%)$-doped $\mathrm{SrTiO}_{3}$ single crystals were attached to copper sample holders and introduced into a measurement chamber under a pressure less than $5 \times 10^{-8} \mathrm{~Pa}$. Since the undoped sample was highly resistive, the conditions of a neutralizer were optimized to obtain XPS spectra. Although the peak positions changed from sample to sample, the spectral profiles exhibited excellent reproducibility.

MO calculations were carried out using a discrete-varia- tional (DV)-X $\alpha$ method. ${ }^{14)}$ The cluster models for the MO calculations were constructed on the basis of the crystal structure of cubic perovskite-type $\mathrm{SrTiO}_{3}$. The lattice parameter was the same as that in bulk, $a=0.3904 \mathrm{~nm} .{ }^{15)}$ The cluster model for the undoped $\mathrm{SrTiO}_{3},\left[\mathrm{Sr}_{7} \mathrm{Ti}_{8} \mathrm{O}_{60}\right]^{74-}$ was composed of 75 atoms. A La-doped cluster $\left[\mathrm{LaSr}_{6} \mathrm{Ti}_{8}\right.$ $\left.\mathrm{O}_{60}\right]^{73-}$ was constructed by substituting $\mathrm{Sr}$ at the center of the cluster with La. The clusters were embedded in a Madelung potential generated by point charges outside the cluster. Electronic structures of the model clusters were self-consistently calculated using numerical atomic basis functions. The atomic orbitals used in the MO calculation were $1 \mathrm{~s}-4 \mathrm{~d}$ orbitals for $\mathrm{Sr}, 1 \mathrm{~s}-4 \mathrm{p}$ orbitals for Ti, $1 \mathrm{~s}-2 \mathrm{p}$ orbitals for $\mathrm{O}$ and $1 \mathrm{~s}-6 \mathrm{p}$ for La. The total charge of the $\left[\mathrm{LaSr}_{6}\right.$ $\left.\mathrm{Ti}_{8} \mathrm{O}_{60}\right]^{73-}$ cluster, $-73 \mathrm{e}$, was obtained by summing the formal charges of the constituents, $\mathrm{Sr}^{2+}, \mathrm{Ti}^{4+}, \mathrm{O}^{2-}$ and $\mathrm{La}^{3+}$. MO energies were normalized with the highest occupied MO (HOMO) being zero. The XPS spectra were calculated by convoluting the discrete energy eigenvalues by $0.3-\mathrm{eV}$ wide Gaussian functions. The partial photoionization cross sections for each atomic orbital were referred from the report by Yeh and Lindau. ${ }^{16)}$

\section{Results and discussion}

Figure 1 (a) shows the valence band (VB) spectrum of the $\mathrm{SrTiO}_{3}$ single crystal. The VB spectrum of as-fractured $\mathrm{SrTiO}_{3}$ exhibited two peaks: $\mathrm{P} 1$ at around $5 \mathrm{eV}$ and $\mathrm{P} 2$ at around $7 \mathrm{eV}$ arising from the $\mathrm{O} 2 \mathrm{p} \pi$ and $\mathrm{O} 2 \mathrm{p} \sigma$ bonding orbitals, respectively. The experimental width of the valence band, determined from both intercepts of linear fits to the left shoulder of peak P1 and the shoulder of peak P2 with the zero line of the samples, was $6 \mathrm{eV}$. These features of the VB spectrum of as-fractured $\mathrm{SrTiO}_{3}$ are in agreement with previously reported XPS and ultraviolet photoemission

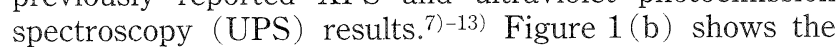
VB spectrum of an as-fractured La-doped $\mathrm{SrTiO}_{3}$ singlecrystal surface. The VB spectra of $\mathrm{SrTiO}_{3}$-doped and undoped samples are similar in shape and width, so the differences between the two spectra are not clear. The only differ- 


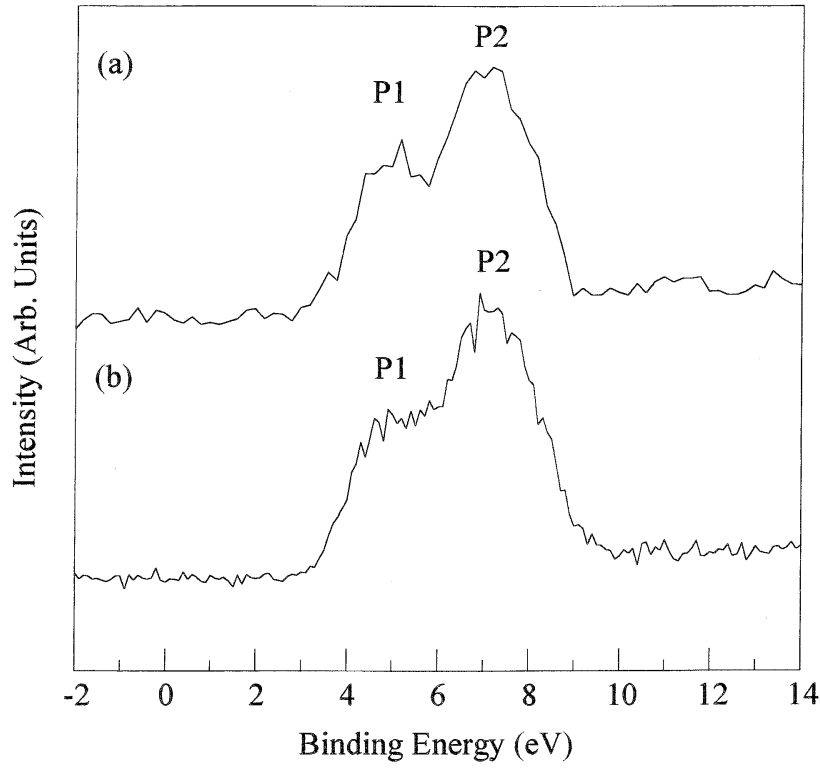

Fig. 1. Valence band spectra of (a) $\mathrm{SrTiO}_{3}$ and (b) La-doped $\mathrm{SrTiO}_{3}$ single crystals.

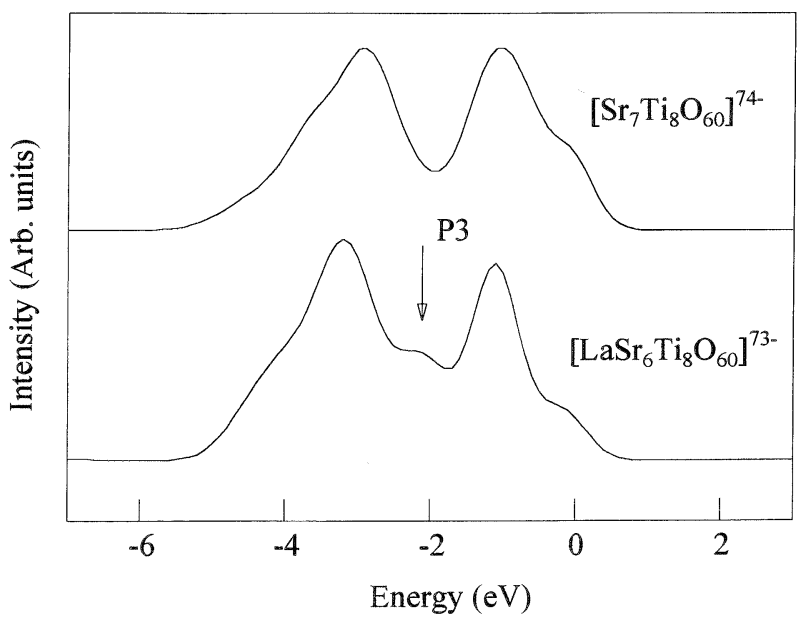

Fig. 2. Calculated valence band spectra of $\left[\mathrm{Sr}_{7} \mathrm{Ti}_{8} \mathrm{O}_{60}\right]^{74-}$ and $\left[\mathrm{LaSr}_{6} \mathrm{Ti}_{8} \mathrm{O}_{60}\right]^{73-}$ clusters.

ence in these spectra is that the valley between $\mathrm{P} 1$ and $\mathrm{P} 2$ exists in the VB spectrum for the undoped $\mathrm{SrTiO}_{3}$ but not for La-doped $\mathrm{SrTiO}_{3}$. This suggests that $\mathrm{La}$ doping produces a new peak at $\sim 6.0 \mathrm{eV}$, between the $\mathrm{P} 1$ and $\mathrm{P} 2$ peaks.

Figure 2 shows the calculated XPS spectra for the $\left[\mathrm{Sr}_{7} \mathrm{Ti}_{8} \mathrm{O}_{60}\right]^{74-}$ and $\left[\mathrm{LaSr}_{6} \mathrm{Ti}_{8} \mathrm{O}_{60}\right]^{73-}$ clusters. Compared with Fig. 1, the calculated spectra of the valence band reproduce well the experimental ones with respect to the bandwidth and the shape. An appreciable difference between the two calculated VB spectra is that a third peak, P3, exists between P1 and P2 for the $\left[\mathrm{LaSr}_{6} \mathrm{Ti}_{8} \mathrm{O}_{60}\right]^{73-}$ cluster. This result corresponds well to the experimentally obtained spectrum for La-doped $\mathrm{SrTiO}_{3}$, because the appearance of peak $\mathrm{P} 3$ obscures the split between $\mathrm{P} 1$ and $\mathrm{P} 2$. In other words, La doping modifies the VB electronic structure of $\mathrm{SrTiO}_{3}$.

Next, we performed a partial density of states (PDOS) calculation for each atomic orbital component in order to reveal the origin of P3. In the PDOS calculation, 3d orbitals for $\mathrm{Ti}$ and $2 \mathrm{~s}-2 \mathrm{p}$ orbitals for $\mathrm{O}$ were used as the atomic basis
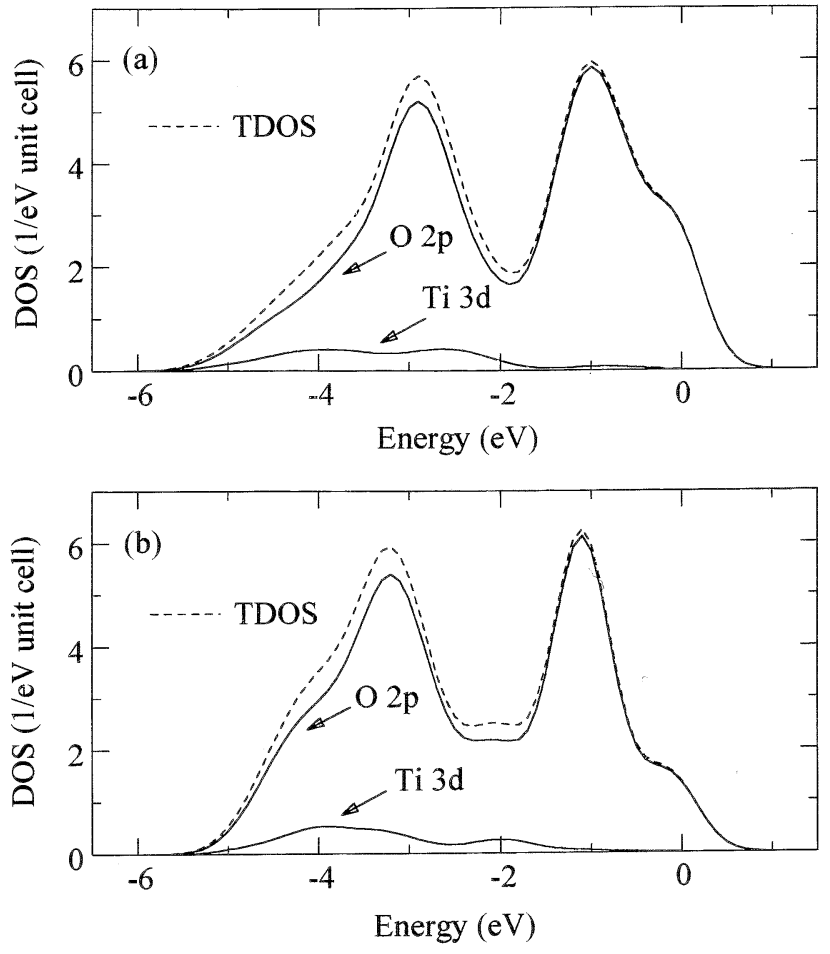

Fig. 3. Total and partial densities of states of (a) $\left[\mathrm{Sr}_{7} \mathrm{Ti}_{8} \mathrm{O}_{60}\right]^{74-}$ and (b) $\left[\mathrm{LaSr}_{6} \mathrm{Ti}_{8} \mathrm{O}_{60}\right]^{73-}$ clusters.

functions. Here, the other atomic orbitals were excluded from the PDOS calculation, since their contributions to the VB spectra can generally be ignored in these materials. The calculated total DOS ( TDOS) and PDOS for the $\left[\mathrm{Sr}_{7} \mathrm{Ti}_{8} \mathrm{O}_{60}\right]^{74-}$ cluster are shown in Fig. 3(a). Two large peaks appear at $-1.0 \mathrm{eV}$ and $-2.9 \mathrm{eV}$, which are assigned to $\mathrm{O} 2 \mathrm{p} \pi$ and $\mathrm{O} 2 \mathrm{p} \sigma$ bonding orbitals, respectively. A separation width between the two peaks agrees with the experimental one. O $2 \mathrm{p}$ orbitals have a high density of states in the VB region and hybridize with Ti $3 \mathrm{~d}$ orbitals. The calculated TDOS and PDOS for the $\left[\mathrm{LaSr}_{6} \mathrm{Ti}_{8} \mathrm{O}_{60}\right]^{73-}$ cluster are shown in Fig. 3(b). Each DOS is partially modified by La doping compared with those in Fig. 3(a). The splitting between the two large peaks is $0.3 \mathrm{eV}$ wider than that of the $\left[\mathrm{Sr}_{7} \mathrm{Ti}_{8} \mathrm{O}_{60}\right]^{74-}$ cluster and a new small peak emerges at $-2.0 \mathrm{eV}$. This small peak can be assigned to the Ti-O interaction, because the PDOS calculation using all atomic orbitals indicates that the atomic orbitals for La contribute very little to the DOS curves in the VB region. Furthermore, we carried out the overlap population analysis for both clusters. The bond overlap population, defined as a sum of the overlap population of occupied orbitals of the nearest Ti-O, are estimated to be 0.028 for the $\left[\mathrm{Sr}_{7} \mathrm{Ti}_{8} \mathrm{O}_{60}\right]^{74-}$ cluster and 0.038 for the $\left[\operatorname{LaSr}_{6} \mathrm{Ti}_{8} \mathrm{O}_{60}\right]^{73-}$ cluster. This result indicates that the covalent bond between $\mathrm{Ti}$ and $\mathrm{O}$ atoms is strengthened by La doping.

References

1) M. Capzzi and A. Frova, Phys. Rev. Lett., 25, 1298-302 (1970).

2) C. Lee, J. Destry and J. L. Brebner, Phys. Rev. B, 11, 2299-310 (1975).

3) A. H. Kahn and A. J. Leyendecker, Phys. Rev., 135A, 1321-25 (1964).

4) T. Wolfram and S. Ellialtioglu, Appl. Phys., 13, 21-24 (1977).

5) S. Ellialtioglu, T. Wolfram and V. E. Henrich, Solid State Commun., 27, 321-24 (1978). 
6) P. Pertosa and F. M. Michel-Calendini, Phys. Rev. B, 17, 2011-20 (1978)

7) F. L. Battye, H. Hochst and A. Goldmann, Solid State Com mun., 19, 269-71 (1976).

8) S. P. Kowalzyk, F. R. McFeely, L. Ley, V. T. Gritsyna and D. A. Shirley, Solid State Commun., 23, 161-69 (1977).

9) W. J. Lo and G. A. Somorjai, Phys. Rev. B, 17, 4942-50 (1978).

10) V. B. Henrich, G. Dresselhaus and H. J. Zeiger, Phys. Rev. B 17, 4908-21 (1978)
11) Y. W. Chung and W. B. Weissbard, Phys. Rev. B, 20, 3456-61 (1979)

12) R. Courths, Phys. Status Solidi B, 100, 135-48 (1980).

13) B. Reihl, J. G. Bednorz, K. A. Muller, Y. Jugnet, G. Landgren and J. F. Morar, Phys. Rev. B, 30, 803-06 (1984).

14) H. Adachi, M. Tsukada and C. Satoko, J. Phys. Soc. Jpn., 45, 875-83 (1978).

15) E. Raub and W. Mahler, Z. Metalk., 46, 282-90 (1955).

16) J. J. Yeh and I. Lindau, At. Data and Nuclear Data Tables, 32 $1-155$ (1985). 